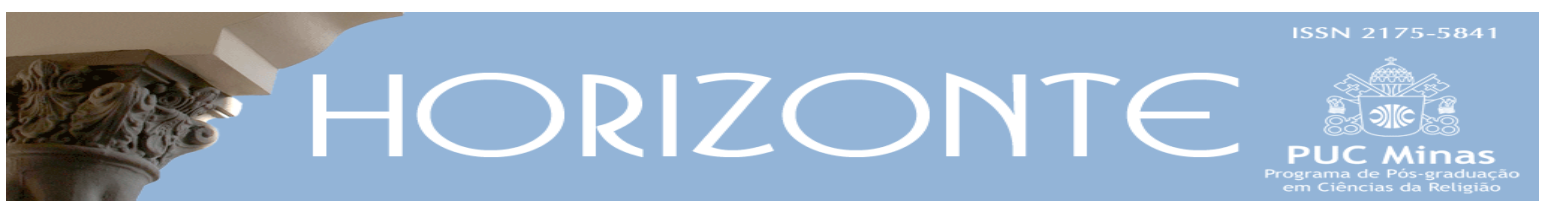

Temática Livre - Artigo original

(c) (i) $\mathrm{DOI}-10.5752 / P .2175-5841.2019 v 17 n 53 p 1039$

\title{
Apego a Deus: revisão integrativa de literatura empírica
}

\author{
Attachment to God: integrative review of empirical literature
}

\author{
Hartmut August* \\ Mary Rute Gomes Esperandio**
}

\begin{abstract}
Resumo
Este artigo apresenta uma revisão da literatura empírica sobre o apego a Deus. O método utilizado foi a revisão integrativa, com levantamento das publicações existentes no período de 1980 a 2017, nas bases BVS, CINAHL, Periódicos CAPES, PsycARTICLES, PubMed, SciELO e SocINDEX. As buscas foram realizadas nos campos "título" e "resumo". Após exame das 254 publicações encontradas, 62 estudos foram selecionados para análise. A discussão da temática foi realizada categorizando os trabalhos de acordo com os objetivos de cada estudo: "construção ou validação de escalas", "ciclos da vida", "saúde mental", "experiência religiosa" e "aconselhamento e cuidado espiritual". O apego parental influencia na maneira como a pessoa irá construir ou não uma relação de apego a Deus. O apego a Deus pode ser um meio para atenuar o sofrimento e para reparar os modelos internos de funcionamento da pessoa. Pessoas com apego seguro a Deus apresentam um aumento sadio da espiritualidade e adotam comportamentos que favorecem a saúde física e emocional. Pessoas com apego inseguro a Deus apresentam instabilidade na espiritualidade e reportam mais aflição, podendo sofrer um declínio na saúde mental. Os conceitos de um Deus que se importa e cuida podem ser empregados para promover maior autonomia e autoconfiança da pessoa. Considerando a importância da religiosidade no contexto cultural brasileiro, o aprofundamento do tema seria de grande relevância para os campos da Teologia, da Psicologia e das Ciências das Religiões.
\end{abstract}

Palavras-chave: Apego; apego a Deus; psicologia da religião; teologia prática.

\begin{abstract}
This article presents a review of the empirical literature on Attachment to God. We used the integrative review method and collected data on existing publications in the period from 1980 to 2017, at BVS, CINAHL, CAPES Journal Portal, PsycARTICLES, PubMed, SciELO and SocINDEX databases. Search was performed in the 'title' and 'abstract' field. After examining the 254 found publications, 62 studies were selected for analysis and categorized into thematic units, according to the focus of each study: "construction or validation of scales", "life cycles", "mental health", "religious experience", and "counseling and spiritual care". Parental attachment influences on how a person will build or not a relationship of attachment to God. Attachment to God may be a form to alleviate suffering and to repair internal working models of the person. People with secure Attachment to God present a healthy increase in spirituality and adopt behaviors that favor physical and emotional health. People with an insecure Attachment to God show instability in spirituality and report more distress, which may cause a decline in mental health. The concepts of a God who cares can be employed to promote greater autonomy and selfconfidence. Considering the importance of religiosity in the Brazilian cultural context, the deepening of the theme would be of great relevance for the fields of Theology, Psychology and Religious Science.
\end{abstract}

Keywords: Attachment; attachment to God; psychology of religion; practical theology.

Artigo submetido em 28 de maio de 2018 e aprovado em 15 de agosto de 2019.

* Doutor em Teologia pela PUCPR. Professor da Faculdade Fidelis e professor colaborador da PUCPR. País de origem: Brasil. E-mail: hartmut.august@fidelis.edu.br

*** Doutora em Teologia pelas Faculdades EST. Professora Adjunta da PUCPR. País de origem: Brasil. E-mail: mary.esperandio@pucpr.br 


\section{Introdução}

Dificilmente ocorre a dois seres apaixonados que sua paixão se relaciona à sua história pessoal, a um certo "estilo" ou tendência para desenvolver determinada forma de relação amorosa. $\mathrm{O}$ modo com o qual uma dada relação amorosa se desenvolve pode ser analisado à luz da chamada "Teoria do Apego", um constructo apresentado por um pesquisador chamado John Bowlby (1907-1990), psicólogo, psiquiatra e psicanalista britânico, que se notabilizou, em meados do século passado, por seu interesse no desenvolvimento da criança. Distanciando-se da psicanálise clássica (BOWLBY, 2004a, p. 37), este psiquiatra percebeu a necessidade de desenvolver uma nova teoria de controle da motivação e do comportamento - a Teoria do Apego (BOWLBY 2002, 2004a, 2004b). O autor afirma que esta teoria tem como base a psicologia do desenvolvimento, a psicologia cognitiva, a biologia evolucionária, a etologia e a teoria dos sistemas de controle.

John Bowlby cresceu em uma família de classe média alta em Londres. Seu pai, um cirurgião-chefe, muitas vezes estava ausente. Bowlby era cuidado principalmente por uma babá e não passava muito tempo com sua mãe, como era costume naquela época. Antes da Segunda Guerra Mundial, ele trabalhou com crianças delinquentes e desajustadas em Londres. Durante a guerra, vários eventos ampliaram seu interesse nas implicações da separação das crianças de seus familiares, incluindo o resgate de crianças judias pela Kindertransport, a evacuação de crianças de Londres para mantêlas a salvo de ataques aéreos e o uso de berçários para permitir que as mães de crianças pequenas contribuíssem com o esforço de guerra. Imediatamente após o término da guerra, Bowlby foi convidado pela Organização Mundial da Saúde a escrever um artigo sobre as dificuldades apresentadas pelas crianças órfãs e sem lar. Assim, ao final da década de 1950, ele havia acumulado um significativo corpo de trabalho teórico e observacional que apontava para a importância dos laços emocionais com um cuidador.

Mais tarde, em contato com a Teoria do Apego, Mary Ainsworth desenvolveu, em colaboração com Bowlby, estudos com crianças em Uganda, sobre o 
desenvolvimento emocional nos primeiros anos da infância. Estes dois autores, portanto, foram os pioneiros nos estudos sobre Apego.

Com base na Teoria do Apego, alguns psicólogos da religião, notadamente Kirkpatrick (2005) e outros, desenvolveram a Teoria do Apego a Deus. O presente estudo tem como objetivo apresentar uma revisão de literatura do tipo integrativa, sobre os estudos empíricos sobre Apego a Deus. Antes, porém, são apresentados brevemente os fundamentos da Teoria do Apego e Apego a Deus.

\section{Bases teóricas do Apego e do Apego a Deus}

Em muitos casos, a palavra "apego" carrega uma conotação negativa, de uma relação imatura e dependente de outra pessoa ou de coisas, indicando uma relação que diminui a liberdade dos indivíduos. Na Teoria do Apego, essa conotação negativa está associada ao que se caracteriza como apego inseguro, sendo este, o oposto ao apego seguro. Este último é desejável, na medida em que favorece o acolhimento saudável e o apoio mútuo nas relações intersubjetivas.

Bowlby propõe que o elemento mais relevante na relação entre a criança e seus pais é o vínculo ou apego que se estabelece entre eles desde a mais tenra idade (BOWLBY, 2004a, p. XVIII). Para ele, "nenhuma forma de comportamento é acompanhada por sentimento mais forte do que o comportamento de apego" (BOWLBY, 2002, p. 259). Assim, Bowlby define como comportamento de apego "qualquer forma de comportamento que resulta na consecução ou conservação, por uma pessoa, da proximidade de alguma outra (pessoa) diferenciada ou preferida" (2004a, p. 38), que com o passar do tempo, faz com que se desenvolvam laços afetivos ou apegos (BOWLBY, 2004a, p. 38). Os comportamentos de apego não são considerados estágios a serem superados ou algo que se desenvolve apenas na infância. O autor afirma que o comportamento de apego é parte integrante do ciclo vital, pois contribui "para a sobrevivência do indivíduo" (BOWLBY, 2004a, p. 40), uma vez que a figura de apego ou cuidador ${ }^{1}$ protege e cuida da pessoa apegada.

\footnotetext{
${ }^{1}$ Quando há referência à figura de apego ou cuidador/a, tem-se em mente a pessoa ou as pessoas responsáveis pelo cuidado e educação da criança. Normalmente será a mãe e o pai. Porém muitas crianças são educadas por outros adultos, como avós, tios,
} 
Estudos conduzidos por Mary Ainsworth (1913-1999) destacaram cinco características para identificar um relacionamento de apego: (1) a pessoa apegada procura proximidade com o cuidador, particularmente quando está assustada ou alarmada; (2) o cuidador proporciona cuidado e proteção, na função de porto seguro; (3) o cuidador proporciona uma sensação de segurança, na função de base segura; (4) a ameaça de separação causa ansiedade na pessoa apegada; (5) a perda da figura de apego causa luto na pessoa apegada (KIRKPATRICK, 2005, p. 56). Portanto, para que um relacionamento seja considerado de apego, o mesmo deve apresentar todas as cinco características citadas. Para além do comportamento de apego, há ainda o que os autores Mikulincer e Shaver (2010) definiram como sistema de apego. Para estes autores, o sistema de apego "consiste num dispositivo de regulação interpessoal" (MIKULINCER; SHAVER, 2010, p. 254). Isto implica em que o indivíduo avalia o progresso que está fazendo em obter apoio e conforto da figura de apego, corrigindo as ações, se necessário, para alcançar os objetivos de obter apoio e conforto. A pessoa chega à idade adulta com grande propensão a manter o mesmo estilo de comportamento identificado quando era criança, pois, "o comportamento de apego na vida adulta é uma continuação direta do comportamento na infância” (BOWLBY, 2002, p. 257). Por essa razão, pode-se afirmar que grande parte dos relacionamentos amorosos tem como motivação de base o estilo de apego que a pessoa desenvolveu na infância.

O sistema de apego pode ser considerado seguro ou inseguro. O apego seguro caracteriza-se pela confiança que o indivíduo tem de que suas figuras de apego estarão disponíveis, responsivas e prestativas, em caso de "situações adversas ou assustadoras" (BOWLBY, 1988, p. 167). O apego seguro se evidencia por um comportamento amoroso, leve e afetivamente suprido no relacionamento de apego. Seu comportamento é caracterizado pelo equilíbrio, pois, sente-se à vontade com a intimidade, ao mesmo tempo que respeita a liberdade e autonomia própria e do outro.

Já o apego inseguro é perpassado por emoções como medo e relutância nas relações intersubjetivas e pode ser classificado como ansioso, evitante ou ansioso-

madrastas e padrastos, mães e pais adotivos e assim por diante. Na vida adulta, outras pessoas irão assumir a função de figura de apego ou cuidador/a, como será visto adiante. 
evitante (desorganizado). O apego ansioso caracteriza-se pela hiperativação do sistema de apego, pois, "o indivíduo não está certo se seus pais (ou outras figuras de apego) estarão disponíveis ou responsivos ou úteis quando chamados" (BOWLBY, 1988, p. 167). Essa incerteza conduz a um comportamento de luta e protesto para obter atenção, amor e apoio da figura de apego, cuja disponibilidade não está assegurada. Com o passar do tempo, as exigências estridentes de apoio começam a parecer naturais e necessárias, podendo se tornar a causa de mais conflitos relacionais e de mais sofrimento emocional.

O apego evitante destaca-se pela repressão ou desativação do sistema de apego na medida em que o indivíduo reage à indisponibilidade da figura de apego mediante $o$ distanciamento emocional. No estilo de apego evitante, "o indivíduo não tem a confiança de que, quando ele procurar atendimento, ele será respondido de maneira útil; pelo contrário, ele espera ser recusado" (BOWLBY, 1988, p. 167). Esse comportamento decorre da compreensão de que a figura de apego desaprova ou pune a proximidade e as expressões de necessidades ou vulnerabilidades. Nessas situações, a busca de proximidade é enfraquecida ou bloqueada e o indivíduo passa a lidar com as ameaças e perigos de forma solitária.

Quanto ao apego ansioso-evitante (ou desorganizado), este distingue-se por comportamentos conflitantes, desorientados ou temerosos. Quando o sistema de apego é ativado, o indivíduo com esse estilo de apego busca a proximidade da figura de apego, ao mesmo tempo que teme essa proximidade. Esse padrão de apego "é mais comum em bebês maltratados, embora não indique necessariamente maus-tratos" (GRANQVIST et al., 2017, p. 3). Traumas ou perdas não resolvidas dos cuidadores também podem contribuir para o apego desorganizado dos filhos, na medida em que a mãe ou o pai apresentam comportamentos sutilmente assustadores, assustados ou dissociativos em relação ao bebê (GRANQVIST et al., 2017, p. 2,3).

Assim, a partir do processo contínuo de construção da experiência pessoal, nossa história passada vai deixando marcas ao longo do tempo, que geram consequências e resultam em padrões e estilos de significado pessoal (ABREU, 2005, p. 14; HAZAN; SHAVER, 1987, p. 515). 
A partir dos estudos iniciados por Kirkpatrick, Shaver, Granqvist e colegas (KIRKPATRICK; SHAVER, 1990, 1992; KIRKPATRICK, 1992, 1997, 1998, 1999, 2005; GRANQVIST, 1998, 2005, 2014; GRANQVIST et al., 2007a, 2007b, 2010, 2012, 2013, 2014), o apego tem sido conceituado como um aspecto relevante também no relacionamento entre a pessoa que crê e Deus. Esses pesquisadores utilizaram a perspectiva da Teoria do Apego para aproximar os campos de pesquisa da ciência da religião com a psicologia cognitiva.

O estudo pioneiro nessa área foi publicado por Kirkpatrick e Shaver em 1990. Eles pesquisaram a correlação entre as experiências de apego na infância e as práticas religiosas na vida adulta. Granqvist (1998) ampliou as pesquisas sobre a influência do apego na infância na religiosidade adulta, concluindo que é possível "haver diferentes caminhos para a religiosidade para pessoas que têm diferentes qualidades de apego na infância" (GRANQVIST, 1998, p. 343). Mais tarde, Kirkpatrick argumentou que "Deus atua efetivamente como uma figura de apego para muitos fiéis" (KRIKPARTRIK, 2005, p. 55), pois, "para muitas pessoas em muitas religiões, este sistema de apego está fundamentalmente envolvido em seus pensamentos, crenças e raciocínios sobre Deus e seu relacionamento com Deus" (KRIKPARTRIK, 2005, p. 55-56).

Miner (2007) propôs ampliar os conceitos da Teoria do Apego à luz da teologia cristã. Ela afirma que "o modelo cognitivo-afetivo de apego a Deus, conforme desenvolvido por Kirkpatrick e seus colegas, sustenta que as representações de Deus estão baseadas em experiências com cuidadores primários" (MINER, 2007, p. 121). Por outro lado, ao se considerar a teologia social contemporânea da Trindade ${ }^{2}$, é possível compreender a existência de um relacionamento de apego entre o crente e Deus. Dessa forma, pode-se considerar o apego a Deus como sendo tanto mediado pelas experiências de apego interpessoais, como direto a partir da construção de um vínculo da pessoa com Deus a partir da sua experiência religiosa (MINER, 2007, p. 121).

No Brasil, um estudo pioneiro sobre apego a Deus é o artigo publicado sob o título “Teoria do Apego e Comportamento Religioso” (ESPERANDIO; AUGUST, 2014).

\footnotetext{
${ }^{2}$ A palavra "Trindade" (no latim, Trinitas) designa a compreensão de um Deus triuno, onde Pai, Filho e Espírito compõem três pessoas que se relacionam entre si em perfeita harmonia. A teologia da Trindade entende que os seres humanos, criados à imagem e semelhança de Deus, trazem em si um sentimento de dependência de Deus e de busca de relacionamento com Ele.
} 
Esse artigo apresenta as principais descobertas sobre a relação entre a constituição subjetiva e o comportamento religioso à luz da Teoria do Apego.

\section{Metodologia}

O método utilizado no presente estudo é a revisão integrativa de literatura. Esse método permite sintetizar o "estado de conhecimento de um determinado assunto, além de apontar lacunas do conhecimento que precisam ser preenchidas com a realização de novos estudos" (MENDES et al., 2008, p. 759).

A pergunta norteadora desta pesquisa foi referente aos achados da literatura empírica, no âmbito nacional e internacional, sobre o apego a Deus. Para esse fim, realizou-se um levantamento das publicações existentes no período de 1980 a 2017. Foram consultadas as seguintes bases de dados: Biblioteca Virtual de Saúde, CINAHL Database, Portal de Periódicos CAPES, PsycARTICLES da American Psychological Association, PubMed - US National Library of Medicine National Institutes of Health, SciELO - Scientific Electronic Library Online FAPESP e SocINDEX. As buscas foram realizadas nos campos "título" e "resumo" das publicações.

Ao empregar-se as expressões "apego" e "Deus", bem como "bindung" e "Gott" (respectivamente "apego" e "Deus", no idioma alemão), não foi localizada qualquer publicação, em todas as bases consultadas. Contudo, ao utilizar os termos de busca "attachment" e "God" (respectivamente "apego" e "Deus", no idioma inglês), foram localizadas 254 publicações. Todos esses trabalhos estavam publicados na língua inglesa. Das bases pesquisadas, 33 publicações foram localizadas no CINAHL, 61 no Periódicos CAPES, 26 no PsycARTICLES, 47 no PubMed, 1 no SciELO e 86 no SocINDEX.

Após minuciosa análise, foram descartados os trabalhos que não se relacionavam diretamente ao tema, os trabalhos que não continham estudos empíricos sobre apego a Deus, as repetições de estudos nas bases pesquisadas e dois estudos que não puderam ser acessados em sua íntegra. Após essas exclusões, chegou-se a 62 estudos empíricos a serem analisados. 


\section{Resultados}

Embora a busca abrangesse publicações a partir de 1980, os primeiros estudos empíricos localizados datam de 2002. Oitenta e quatro por cento dos trabalhos (52 estudos) foram publicados a partir de 2009. O gráfico 1 apresenta as publicações por ano.

Gráfico 1 - Publicações sobre Apego a Deus, por Ano3

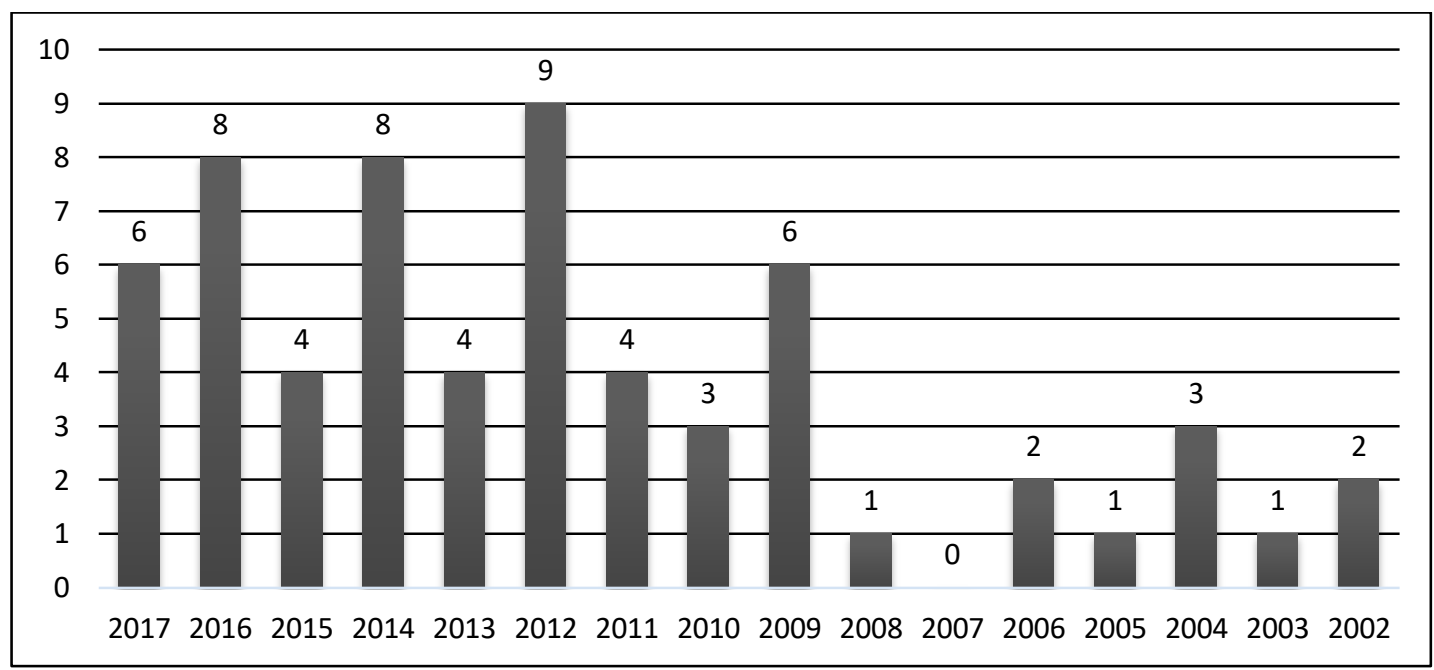

Fonte: Elaborado pelos autores.

Há um claro domínio dos $\operatorname{EUA}(71 \%)$ e Inglaterra (24 \%), como os países com mais publicações de trabalhos empíricos sobre apego a Deus.

Com relação à escala utilizada para a coleta dos dados, a Attachment to God Inventory (BECK; MCDONALD, 2004) foi empregada em 27 publicações, a Dimensions of Attachment to God (ROWATT; KIRKPATRICK, 2002) em 16 publicações, a Three Brief Forced-choice Attachment-to-God Paragraphs (KIRKPATRICK; SHAVER, 1992) em 5 publicações, a Attachment to God Measure (SIM; LOH, 2003) em 2 publicações, a Relationship with God Scale (BELAVICH; PARGAMENT, 2002) em 2 publicações, a God Attachment Interview Schedule (PROCTOR et al., 2009) em uma publicação e a Muslim Spiritual Attachment Scale

\footnotetext{
${ }^{3}$ Em 2017, foram consideradas as publicações até 12/07/17.
} 
(MINER et al., 2017) em uma publicação. Oito estudos realizaram a coleta dos dados a partir de um instrumento não validado.

As publicações podem ser organizadas em cinco grandes categorias: "construção ou validação de escalas", "ciclos da vida", "saúde mental", "experiência religiosa" e "aconselhamento e cuidado espiritual".

\subsection{Construção ou validação de escalas de mensuração do apego a Deus}

Seis trabalhos (ROWATT; KIRKPATRICK, 2002; SIM; LOH, 2003; BECK; MCDONALD, 2004; PROCTOR et al., 2009; KIM et al., 2017; MINER et al., 2017) tratam da construção ou validação de escalas de mensuração do apego a Deus.

O instrumento Attachment to God Scale(AGS) foi construído por Rowatt; Kirkpatrick (2002, p. 647) a partir das três categorias de apego descritas por Kirkpatrick; Shaver (1992): seguro, evitante e ansioso. Os autores partiram do princípio de que as dimensões de ansiedade e de evitação no apego a Deus são preditivos significativos para a mensuração desse apego (ROWATT; KIRKPATRICK, 2002, p. 647).

Sim; Loh (2003) construíram a escala Attachment To God Measure (AGM) a partir das quatro características de uma relação de apego a Deus propostas por Kirkpatrick (1999): Deus como porto seguro, Deus como base segura, a busca e manutenção de proximidade com Deus, e a resposta à separação de Deus (SIM; LOH, 2003, p. 379).

Tendo como ponto de partida o instrumento Experiences in Close Relationships Scale, de Brennan et al. (1998), Beck; McDonald (2004) desenvolveram a Attachment To God Inventory (AGI). A AGI consiste num instrumento que mensura a evitação e a ansiedade no relacionamento da pessoa com Deus. Kim et al. (2017) validaram a AGI junto a coreanos cristãos que imigraram para os EUA. Em seus estudos, a escala somente apresentou índices confiáveis após a exclusão de 17 dos 28 itens. A hipótese levantada pelos autores é de que a escala original não apresentou aderência necessária, tendo em vista que o imigrantes coreanos mantêm tradições espirituais e religiosas 
diferentes da tradição norte-americana (KIM et al., 2017, p. 21), o que pode ter influenciado nas respostas aos itens do instrumento (KIM et al., 2017, p. 23).

O instrumento God Attachment Interview Schedule (GAIS) desenvolvido por Proctor et al. (2009) consiste num protocolo de entrevista semiestruturada. Ele leva em consideração situações ocorridas no relacionamento da pessoa com Deus ao longo das diversas fases da vida, empregando a perspectiva do desenvolvimento do apego a Deus e procurando identificar situações que possam caracterizar apegos seguros, ansiosos ou evitantes em relação a Deus.

Visto que os instrumentos de mensuração do apego a Deus até então disponíveis foram construídos levando em consideração a compreensão que pessoas cristãs tem de Deus, Miner et al. (2017, p. 184) elaboraram a Muslim Spiritual Attachment Scale (MSAS), direcionada para muçulmanos (MINER et al., 2017, p. 184). Essa escala contempla as dimensões de busca por proximidade, porto seguro, base segura, protesto pela separação, modelo positivo de Deus e modelo positivo do self.

Há uma boa gama de instrumentos disponíveis para mensurar o apego a Deus. Contudo, até recentemente a maioria dessas escalas havia sido construída junto a comunidades cristãs e predominantemente protestantes. Em período recente, tem surgido validações que adaptam essas escalas para outros contextos culturais. É o caso da validação da AGI para a Coreia (KIM et al., 2017).

\subsection{Apego a Deus e os ciclos da vida}

Vinte publicações pesquisaram o apego a Deus nos diferentes ciclos da vida. Essas publicações foram agrupadas nos seguintes ciclos: "infância”, "adolescência e juventude", "vida adulta" e "idosos".

\subsubsection{Infância}

Três publicações (REINERT; EDWARDS, 2009; LIMKE; MAYFIELD, 2011; CASSIBBA et al., 2013) pesquisaram o apego a Deus na infância. 
Reinert e Edwards (2009) descobriram que maus tratos verbais, físicos e sexuais estão relacionados a dificuldades na compreensão do apego a Deus de um indivíduo. Aqueles que relataram maus tratos sexuais na infância, comparado àqueles que relataram mau trato verbal ou físico, exibiram a associação mais dramática e adversa com as variáveis de religiosidade e tenderam a relatar maior evidência de um apego mais inseguro a Deus, assim como a presença de conceitos de um Deus menos amoroso, mais controlador e distante (REINERT; EDWARDS, 2009, p. 30-31).

Limke e Mayfield (2011) pesquisaram as influência dos pais e das mães no apego a Deus dos filhos. Sua conclusão foi que "o apego ao pai predisse o apego a Deus. Além do mais, o apego a Deus predisse o bem-estar religioso e existencial da pessoa" (LIMKE; MAYFIELD, 2011, p. 122). Já Cassibba et al. (2013) chegaram a uma conclusão diversa, ao identificar que o sentimento de proximidade de Deus é predito pelo apego seguro das crianças às suas mães.

Embora não haja consenso entre os pesquisadores se o apego a Deus é influenciado mais pelo apego da criança ao pai ou à mãe, os autores citados são unânimes no entendimento de que as relações afetivas parentais da criança desempenham um papel fundamental na maneira como essa criança, ao chegar à idade adulta, irá construir ou não uma relação de apego com Deus.

\subsubsection{Adolescência e juventude}

Seis estudos (REINERT, 2005; BECK, 2006b; SIM; YOW, 2011; REINERT; EDWARDS, 2012; HORTON et al., 2012; KNABB; PELLETIER, 2014) investigaram as relações de apego a Deus na fase da adolescência ou juventude.

Reinert (2005) investigou, junto a um grupo de jovens seminaristas, a correlação entre seus apegos parentais na infância e a posterior representação de si e dos seus relacionamentos com Deus. Em sua pesquisa, as pessoas seguras "relataram níveis significativamente elevados de consciência de Deus, indicando que o apego seguro à mãe levou a um senso maior de conexão com Deus" (REINERT, 2005, p. 235). Por outro lado, o "apego ansioso à mãe estava claramente associado a níveis altos de frustração com Deus" (REINERT, 2005, p. 235). Por fim, a combinação de apego 
evitante à mãe e apego ansioso ao pai parece ser a "dinâmica principal que leva a níveis mais elevados de instabilidade no relacionamento com Deus" (REINERT, 2005, p. 235).

Focalizando no conceito de Deus como base segura, Beck (2006b) observa que os participantes do estudo (universitários, com idade média de 18 anos) que viam Deus como uma base segura estavam mais engajados em exploração teológica e eram mais tolerantes em relação a crenças cristãs diferentes das suas. Esses participantes também reportaram mais paz e menos aflição ao longo de sua jornada espiritual. Contudo, apesar dessa exploração, esses participantes estavam totalmente engajados nas doutrinas centrais do cristianismo (BECK, 2006b, p. 125).

Sim e Yow (2011) identificaram que adolescentes com apego seguro a Deus tendem a apresentar autoestima mais elevada, ao contrário de adolescentes com apego inseguro a Deus (SIM; YOW, 2011).

Com o propósito de aprofundar a compreensão da relação entre apego parental e apego a Deus, os resultados da pesquisa de Reinert e Edwards (2012) sugerem que “no apego a Deus e no conceito de Deus como um Deus amoroso, o nível de segurança do apego ao progenitor do mesmo sexo é mais influente do que o apego parental do sexo oposto, tanto para filhos como para filhas" (REINERT; EDWARDS, 2012, p. 266), contrariando os achados de Limke; Mayfield (2011) e Cassibba et al. (2013). Ou seja, o apego a Deus dos filhos de sexo masculino seria influenciado principalmente pelo apego do filho com seu pai, ao passo que o apego a Deus das filhas seria influenciado principalmente pelo apego da filha com sua mãe.

Horton et al. (2012) identificaram que os apegos evitante e ansioso a Deus estão associados a níveis mais elevados de consumo de bebidas alcoólicas entre jovens. Além disso, o apego ansioso a Deus está associado ao uso de maconha e o apego evitante a Deus está associado ao uso de drogas antes da relação sexual. Num estudo junto a estudantes de uma universidade cristã, Knabb; Pelletier (2014) concluíram que o apego ansioso a Deus prediz tanto o uso problemático da Internet como a aflição emocional (KNABB; PELLETIER, 2014, p. 243). Em ambos estudos, a existência de apegos 
seguros com Deus está associada a uma menor incidência de comportamentos problemáticos na juventude.

Os autores dos seis estudos citados são unânimes no entendimento de que as relações afetivas parentais do adolescente ou jovem desempenham um papel fundamental na maneira como ele irá construir ou não uma relação de apego com Deus. Adolescentes e jovens seguramente apegados a Deus apresentaram maior autoestima, níveis significativamente mais elevados de consciência de Deus, se engajam mais em exploração teológica sadia, são mais tolerantes em relação a outras crenças e reportam mais paz. Por outro lado, adolescentes com apegos inseguros com seus pais apresentaram altos níveis de frustração com Deus, elevados níveis de instabilidade no relacionamento com Deus e reportam mais aflição.

\subsubsection{Vida adulta}

Seis estudos (BIRGEGARD; GRANQVIST, 2004; CASSIBBA et al., 2008; SANDAGE et al., 2015; NJUS; OKERSTROM, 2016; RASHIDI et al., 2016, KENT et al., 2016) pesquisaram o apego a Deus na fase adulta.

As pesquisas junto a pessoas adultas, conduzidas por Birgegard; Granqvist (2004), Cassibba et al. (2008) e Sandage et al. (2015), concordam que há correspondência entre o apego a pai/mãe e o apego a Deus. Sendo que Cassibba et al. (2008) identificaram que o apego seguro está positivamente relacionado a percepções de Deus como amoroso (CASSIBBA et al., 2008, p. 1760). E, para Sandage et al. (2015), "o apego adulto evitante correlacionou-se positivamente com a evitação a Deus e o apego adulto ansioso correlacionou-se positivamente com a dimensão da ansiedade do apego a Deus" (SANDAGE et al., 2015, p. 803).

Njus; Okerstrom (2016), ao correlacionarem o apego a Deus com fundamentos morais, perceberam que pessoas com apego ansioso a Deus davam mais valor a questões de lealdade, autoridade e pureza (NJUS; OKERSTROM, 2016, p. 237-240). Por outro lado, pessoas com apego evitante a Deus davam menos valor aos aspectos de cuidado, cordialidade, autoridade e pureza (NJUS; OKERSTROM, 2016, p. 240). Kent et al. (2016) pesquisaram a relação entre apego a Deus e satisfação profissional. Os 
resultados da pesquisa indicam que um apego seguro com Deus é um preditor positivo do comprometimento afetivo no trabalho e da satisfação no trabalho (KENT et al., 2016, p. 356).

Rashidi et al. (2016) identificaram em sua pesquisa que pessoas com apego seguro a Deus estavam mais propensas a perdoar e a serem empáticas, em comparação com as pessoas com apegos evitantes e ansiosos a Deus (RASHIDI et al., 2016, p. 18).

Assim como já identificado nas fases anteriores, também na vida adulta o apego a Deus é influenciado pelos apegos interpessoais. Por outro lado, o estilo de apego a Deus influencia a maneira como a pessoa se comporta nas relações interpessoais, podendo dar maior ou menor valor a questões morais como lealdade, autoridade, pureza, cordialidade e pureza e estando mais propensa a perdoar e a serem empáticas.

\subsubsection{Idosos}

Foram encontradas 4 publicações (CICIRELLI, 2004; BRUCE et al., 2011; KENT et al., 2017; BRADSHAW; KENT, 2017) que pesquisaram o apego a Deus junto a idosos.

Cicirelli (2004, p. 371) e Bruce et al. (2011, p. 224) concordam que o apego a Deus varia de uma denominação cristã para outra. Cicirelli observou também que "participantes de denominações protestantes fundamentalistas ou evangélicas apresentaram um apego mais forte a Deus do que participantes de outros grupos religiosos" (CICIRELLI, 2004, p. 371).

Ao estudar a relação entre apego a Deus, oração e bem-estar psicológico entre idosos, Bradshaw; Kent (2017), confirmando os achados de Ellison et al. (2014), concluíram que pessoas com apego seguro a Deus e que oram frequentemente, obtêm benefícios claros para sua saúde mental. Pessoas que oram com frequência percebem que Deus estará lá para protegê-las e consolá-las, de modo que elas podem encontrar alívio na oração e podem escolher comportamentos que promovam a saúde de acordo com os ensinamentos religiosos ou inspirações recebidas durante a oração. Em contraste, pessoas que, em momentos difíceis, oram na tentativa de forjar um 
relacionamento com um outro divino que eles não acreditam estar lá, podem sentir um profundo sentimento de distanciamento, podendo sofrer um declínio na saúde mental (BRADSHAW; KENT, 2017, p. 14-17).

Kent et al. (2017) identificaram que entre idosos o apego seguro a Deus está associado ao aumento do otimismo e da autoestima. Portanto, a segurança do apego a Deus pode contribuir para o bem-estar mental positivo (como já identificado por ELLISON et al., 2014; BRADSHAW; KENT, 2017). Além disso, para aqueles que se sentem perdoados por Deus, apegos mais seguros a Deus equivalem a níveis mais altos de bem-estar psicológico (KENT et al., 2017, p. 17). Há também uma substituição das figuras de apego e uma redução nos apegos ansiosos (id), sendo que, para alguns, Deus assume a função de figura de apego primária (KENT et al., 2017, p. 16).

Os estudos confirmam que as figuras de apego são importantes para a adaptação à velhice. Nessa fase da vida, podem ocorrem mudanças nas figuras de apego, sendo que um apego seguro a Deus contribui para um comportamento que favorece a saúde e o aumento do otimismo, da autoestima e do bem-estar psicológico. Em contraste, pessoas com apegos inseguros a Deus podem sentir um profundo sentimento de distanciamento, podendo sofrer um declínio na saúde mental.

\subsection{Apego a Deus e saúde mental}

Entre os 20 estudos encontrados nessa categoria, dois temas se sobressaem: transtorno dismórfico e transtornos alimentares (com sete publicações) e coping (com cinco publicações).

\subsubsection{Transtorno dismórfico e transtornos alimentares}

Sete publicações (HOMAN; BOYATZIS, 2010; HOMAN, 2012; HOMAN; LEMMON, 2014; HOMAN; LEMMON, 2015; STRENGER et al., 2016; KRAUSE; HAYWARD, 2016; BUSER; BIGSON, 2016) apresentam resultados de pesquisas na área do transtorno dismórfico ou de transtornos alimentares. 
Homan; Boyatzis (2010) perceberam que mulheres com apego seguro a Deus apresentam níveis reduzidos de transtornos alimentares. A pesquisa demonstrou também "que a pressão para ser magra e a internalização de ser idealmente magra predisseram descontentamento com o corpo apenas para mulheres com apego ansioso a Deus" (HOMAN; BOYATZIS, 2010, p. 239). Homan (2012) conduziu outro estudo para testar em que medida o estilo de apego a Deus atenua os efeitos negativos da exposição à imagem do corpo ideal feminino na mídia. "Os resultados deste estudo indicam que sentir-se amada e aceita por Deus modera os sentimentos negativos em relação ao corpo" (HOMAN, 2012, p. 328).

Homan; Lemmon (2014) concluem que "quanto mais ansiedade uma mulher vivencia no seu relacionamento com Deus, mais ela se compara com pessoas à sua volta nessas dimensões relacionadas ao corpo" (HOMAN; LEMMON, 2014, p. 352). Mulheres com apego seguro a Deus apresentam menos sentimentos negativos com relação ao corpo e estão menos pressionadas pela comparação social (HOMAN; LEMMON, 2014, p. 355). Outro estudo concluiu que, "quanto mais as mulheres comparavam seus próprios corpos, suas escolhas alimentares e seus hábitos de prática de exercícios com seus colegas, menor era sua apreciação corporal” (HOMAN; LEMMON, 2015, p. 434). Essa associação era maior para as mulheres que se sentiam incertas sobre o amor e a responsividade de Deus e menor para as mulheres que se sentiam incondicionalmente amadas e aceitas por Deus (HOMAN; LEMMON, 2015, p. 434). Strenger et al. (2016, p. 31) também identificaram que a ansiedade no apego a Deus de mulheres estavam associadas aos sintomas dos transtornos alimentares.

Buser; Gibson (2016) observaram ligações significativas entre apegos ansiosos e evitantes a Deus / Poder superior e sintomas bulímicos, diferente de Homan; Boyatzis (2010) que não haviam encontrado suporte para o vínculo entre o apego evitante a Deus e a bulimia (BUSER; GIBSON, 2016, p. 131,132).

Krause; Hayward (2016) observaram em sua pesquisa que os participantes com apego ansioso a Deus são mais propensos a serem obesos se receberem pouco apoio espiritual de seus correligionários. No entanto, os dados revelam que a relação entre apego ansioso a Deus e obesidade enfraquece à medida que o nível de apoio espiritual da comunidade religiosa aumenta (KRAUSE; HAYWARD, 2016, p. 11). 
Os estudos referentes ao cuidado com o corpo demonstram que a existência de um apego seguro a Deus contribui positivamente em todas as questões relacionadas ao corpo e à imagem do corpo ideal. Portanto, sentir-se incondicionalmente amada e aceita por Deus ajuda a preservar a apreciação do corpo pelas mulheres em meio aos desafios da comparação social.

\subsubsection{Coping (enfrentamento)}

Cinco estudos (BELAVICH; PARGAMENT, 2002; COOPER et al., 2009; KELLEY; CHAN, 2012; ANO; PARGAMENT, 2013; CASSIBBA et al., 2014) pesquisaram a relação entre apego a Deus e coping espiritual/religioso.

Belavich; Pargament (2002) identificaram que pessoas de apego seguro a Deus utilizaram "mais o coping espiritual e um estilo de coping mais colaborativo" e também expressaram níveis mais baixos de descontentamento religioso" (BELAVICH; PARGAMENT, 2002, p. 24). Pessoas de apego ansioso ou evitante a Deus "expressaram níveis mais elevados de descontentamento religioso e manifestaram um estilo de coping mais autodirigido", que enfatiza a responsabilidade do indivíduo em resolver um problema sem o auxílio de Deus (BELAVICH; PARGAMENT, 2002, p. 24). Além disso, pessoas de apego ansioso a Deus "podem ter visto a situação como evidência do papel inconsistente de Deus em fornecer apoio, e reagiram a isso com raiva, em vez de buscar esse apoio" (BELAVICH; PARGAMENT, 2002, p. 24).

Cooper et al. (2009) também identificaram a raiva como uma reação dos ansiosamente apegados a Deus (COOPER et al., 2009, p. 134). Além disso, os autores perceberam que as pessoas com apegos a Deus seguros ou ansiosos "usaram mais atividades e ideias cristãs para o coping" (COOPER et al., 2009, p. 134). Outra descoberta foi que as pessoas de apego seguro a Deus "voltaram-se para a religião para evitar problemas, ao passo que os evitantes focaram mais em boas obras e também evitaram qualquer sentido de apelo" a Deus (COOPER et al., 2009, p. 134).

Kelley e Chan (2012) observaram que "o estilo seguro de apego a Deus foi associado a menor depressão e aflição no luto e a um maior crescimento relacionado ao estresse" (KELLEY; CHAN, 2012, p. 199). Por outro lado, pessoas com apego inseguro 
a Deus e neuroticismo estavam mais propensas a fazer avaliações negativas de uma situação estressante e a classificar esses eventos como batalhas espirituais (ANO; PARGAMENT, 2013, p. 419).

Ao estudar o papel do apego a Deus nos processos de coping de pacientes com doenças graves, Cassibba et al. (2014) concluem que “a segurança no apego a Deus está relacionada não apenas com o coping religioso/espiritual, mas também com as formas seculares de coping de uma doença grave” (CASSIBBA et al., 2014, p. 258). Ficou evidenciado que "um apego seguro a Deus estava ligado ao espírito de luta e tendia a estar ligado ao fatalismo. Em contraste, um apego inseguro a Deus tendia estar ligado à desesperança e preocupação ansiosa” (CASSIBBA et al., 2014, p. 258).

As pesquisas, portanto, identificaram que pessoas de apego seguro a Deus utilizaram mais o coping espiritual e colaborativo para enfrentar as situações. Também apresentaram menos descontentamento religioso, menor depressão e aflição no luto e maior crescimento relacionado ao estresse. Por outro lado, pessoas de apegos inseguros a Deus expressaram níveis mais elevados de descontentamento religioso, manifestaram um estilo de coping mais autodirigido, tendendo a classificar os eventos estressantes como sendo conflitos espirituais, dando espaço à raiva, desesperança e preocupação ansiosa.

\subsubsection{Demais estudos em saúde mental}

Nove estudos (DUMONT et al., 2012; ELLISON et al., 2014; REINER et al., 2010; WEI et al., 2012; BRADSHAW et al., 2010; ELLISON et al., 2012; PROUT et al., 2012; FERGUS; ROWATT, 2014; HOMAN, 2014) abordaram diferentes temas relacionando o apego a Deus com a saúde mental.

Dumont el al. (2012) estudaram a relação entre apego a Deus e um ambiente familiar alcoólico. Os pesquisadores identificaram que "o apego seguro a Deus pode anular os efeitos de ser criado num lar alcoólico” (DUMONT et al., 2012, p. 51).

Tanto Bradshaw et al. (2010) como Ellison et al. (2012) pesquisaram a associação entre apego a Deus e angústia. Ambos os estudos concordam que um apego 
seguro a Deus está associado com a redução da angústia e que um apego seguro a Deus amortece os efeitos danosos de eventos estressantes da aflição (BRADSHAW et al., 2010, p. 1; ELLISON et al., 2012, p. 493).

Ellison et al. (2014) perceberam que as pessoas que oram frequentemente a um Deus percebido como uma figura de apego seguro obtêm benefícios claros para sua saúde mental, enquanto aqueles que oram para um Deus percebido como distante experimentam níveis elevados de sintomas relacionados à ansiedade (ELLISON et al., 2014, p. 126).

Dois estudos (REINER et al., 2010; WEI et al., 2012) trataram da relação entre apego a Deus e estresse. Os estudos de Reiner et al. (2010) evidenciam a forte associação entre estresse percebido, apegos adultos ansioso e evitante e apego ansioso a Deus. Por outro lado, em sua pesquisa junto a chineses que migraram aos EUA, Wei et al. (2012) identificaram uma interação significativa entre o estresse percebido e o apego evitante a Deus em termos de satisfação com a vida (WEI et al., 2012, p. 162), sendo que o apego seguro a Deus está diretamente associado à satisfação na vida e aos afetos positivos (WEI et al., 2012, p. 174).

Numa pesquisa sobre apego a Deus e psicose, Prout et al. (2012) observaram que o apego seguro a Deus pode amortecer o relacionamento entre as representações parentais punitivas e a recuperação. Essa descoberta fornece suporte para a hipótese de compensação sobre o apego a Deus (KIRKPATRICK; SHAVER, 1990; KIRKPATRICK, 2005). Os resultados deste estudo também sugerem que existem aspectos da religião e da espiritualidade potencialmente úteis para pacientes com psicose. A ideia de que o apego seguro a Deus possa enfraquecer o relacionamento entre as representações punitivas dos objetos parentais e a recuperação é importante para o conceito de um tratamento holístico e espiritualmente integrador para a psicose (PROUT et al., 2012, p. 461).

Escrupulosidade é um subtipo moral/religioso do Transtorno Obsessivo Compulsivo (TOC), caracterizado por "dúvidas persistentes com relação ao pecado e impulsos irresistíveis para colocar em prática um comportamento excessivamente religioso" (FERGUS; ROWATT, 2014, p. 230). Os autores identificaram que 
“indivíduos escrupulosos estão particularmente propensos a vivenciar apegos ansiosos em relacionamentos próximos e com relação a Deus” (FERGUS; ROWATT, 2014, p. 234).

Numa interessante pesquisa feita para analisar o papel da autocompaixão na relação entre apego a Deus e ansiedade, depressão e satisfação na vida, Homan (2014) percebeu que "as pessoas que respondem às incertezas sobre a disponibilidade de Deus com aflição elevada (ansiedade) ou supressão de emoções (evitação) estão menos propensas a responder às suas próprias falhas com gentileza e compreensão” (HOMAN, 2014, p. 985). Dessa maneira, as pessoas tratam a si mesmas de uma maneira consistente com a maneira como ela entende que foi tratada pela sua figura de apego, pois "as pessoas desenvolvem uma autorrepresentação que integra as qualidades e reações da figura de apego" (HOMAN, 2014, p. 985). Essa autorrepresentação permite que pessoas que veem Deus como amoroso, receptivo e disponível mantenham um senso de autoestima positiva enquanto reconhecem suas próprias fraquezas e deficiências. Por outro lado, "pessoas que têm um histórico de interações em que Deus é visto com olhos de rejeição ou desaprovação irão incorporar essas qualidades em seu próprio autoconceito, tornando-se provável que elas tratarão a si mesmas com desaprovação ou desdém” (HOMAN, 2014, p. 985).

Os diferentes estudos coletados nessa categoria confirmam uma forte correlação entre os estilos de apego e a saúde mental. As pesquisas indicam que a indisponibilidade de figuras de apego interpessoal, estresse e outros fatores que intensificam a ativação do apego e aumentam a força dos vínculos observados entre saúde mental e religião. A crença em um Deus pessoal e amoroso com quem a pessoa experimenta um relacionamento próximo e seguro contribui para a saúde mental do indivíduo. $\mathrm{O}$ apego a Deus pode ser um meio importante para atenuar o sofrimento e para reparar os modelos internos de funcionamento da pessoa após uma perda ou por causa de experiências de abandono por outras figuras de apego. 


\subsection{Apego a Deus e experiência religiosa}

As treze publicações que pesquisaram a relação entre apego a Deus e a experiência religiosa foram agrupados de acordo com os temas "comportamento religioso" e "vida em comunidade".

\subsubsection{Comportamento religioso}

Foram encontradas nove publicações (BECK, 2006a; HALL et al., 2009; GRANQVIST et al., 2012; HOUSER; WELCH, 2013; FREEZE; DITOMMASO, 2014; JANKOWSKI; SANDAGE, 2014; SANDAGE et al., 2015; MONROE; JANKOWSKI, 2016; GHORBANI et al., 2016) que pesquisaram o comportamento religioso em conexão com o apego a Deus. Beck (2006) observou que a existência de comunhão e queixa do indivíduo em seu contato com Deus são elementos que podem proporcionar a esse relacionamento uma dinâmica emocional parecida com aquela observada nos relacionamentos amorosos humanos (BECK, 2006, p. 34).

Na tentativa de clarificar os modelos de conversão por correspondência ou por compensação propostos por Kirkpatrick (2005), Hall et al. (2009) observaram que pessoas com histórico de apego inseguro na infância tendem a buscar Deus como forma de suprir lacunas não preenchidas na infância, adotando o modelo da compensação. Por outro lado, pessoas com histórico de apegos seguros na infância tendem a buscar um relacionamento com Deus como forma de transferência dos relacionamentos vividos, adotando o modelo da correspondência (HALL et al., 2009, p. 227).

Granqvist et al. (2012) examinaram as implicações da Teoria do Apego para aspectos psicológicos da religião entre judeus israelenses. Seus achados indicam que indivíduos mais seguros têm acesso mais rápido a uma base positiva/segura do esquema de Deus, enquanto indivíduos evitantes, e especialmente indivíduos evitantes altamente religiosos, têm acesso mais rápido a uma base negativa/controladora do esquema de Deus (GRANQVIST et al., 2012, p. 812). 
Em sua pesquisa junto a estudantes universitários, Houser; Welch (2013) identificaram que pessoas com apego seguro a Deus expressaram níveis mais elevados de esperança e maior frequência no engajamento de comportamentos religiosos, resultando no fortalecimento do apego a Deus (WELCH, 2013, p. 291). Ao pesquisar um grupo de batistas, Freeze; Ditommaso (2014) também concluíram que "um apego seguro a Deus está associado com um aumento na religiosidade e na espiritualidade" e, por conseguinte, "a uma redução na angústia emocional" (FREEZE; DITOMMASO, 2014, p. 699-700).

Em sua pesquisa, Houser e Welch (2013) constataram que o engajamento em oração e leitura das Escrituras estão mais diretamente relacionados ao desejo pessoal de conexão com Deus, ao passo que a participação nos cultos e missas não demonstrou contribuir para a segurança do apego a Deus (HOUSER; WELCH, 2013, p. 293). Eles perceberam também que pessoas ansiosamente apegadas a Deus são os melhores candidatos a desenvolver um apego compensatório com Deus, ao utilizar Deus na regulação emocional. Além disso, pessoas ansiosamente apegadas a Deus tendem a desenvolver uma visão positiva dos outros, inclusive de Deus, o que favorece a esperança e o maior engajamento em comportamentos religiosos. Por outro lado, divergindo das conclusões propostas Kirkpatrick (2005) e Hall et al. (2009) de que pessoas com apegos inseguros na infância tenderiam a desenvolver um apego compensatório com Deus, Houser; Welch (2013) perceberam que pessoas com apego evitante a Deus não se enquadravam nessa hipótese, pois apresentaram níveis menores de esperança e menor frequência no engajamento de comportamentos religiosos em relação aos outros estilos de apego a Deus (HOUSER; WELCH, 2013, p. 292, 293). Melissa Kelley (2009), em seu estudo de caso, já havia apontado para o fato de que muitas pessoas com apegos interpessoais inseguros tenderiam a ter dificuldades na construção de um apego seguro com Deus.

Jankowski; Sandage (2014) avaliaram a correlação entre apego a Deus e humildade. Eles perceberam que a instabilidade espiritual, compreendida como sendo uma menor consciência de Deus e um aumento das experiências de frustração e desapontamento em relação de Deus, é um indicador da existência de um apego inseguro com Deus (JANKOWSKI; SANDAGE, 2014, p. 78). Outro estudo sobre 
humildade conduzido por Sandage et al. (2015) identificou que "apego inseguro e fome por idealização são expressões de espiritualidade que são incompatíveis com a humildade" (SANDAGE et al., 2015, p. 215). Esses estudos estão consistentes com o entendimento de que a humildade é um elemento da individualidade relacional, onde a pessoa tem uma correta avaliação de si e um relacionamento seguro com Deus.

Monroe; Jankowski (2016) estudaram o comportamento de apego entre participantes de um programa de intervenção através da oração, num contexto pentecostal. A participação no programa ampliou a proximidade com Deus, associado ao aumento nos afetos positivos e à redução da angústia (MONROE; JANKOWSKI, 2016, p. 237).

Uma publicação (GHORBANI et al., 2016) analisou o apego a Deus no islamismo. "Na maioria das vezes, este estudo deixou claro que estruturas de apego podem fornecer compreensões úteis para tradições religiosas que não fazem parte do Ocidente" (GHORBANI et al., 2016, p. 325). Portanto, a aplicação no islamismo de instrumentos de medição validados em contextos ocidentais cristãos precisa ser conduzida com cautela, tendo em vista, não somente as diferenças culturais entre o Ocidente e outras culturas, como também entre as concepções de Deus como revelado na Bíblia e as concepções do divino em outras religiões.

\subsubsection{Vida em comunidade}

Três publicações (NAMINI; MURKEN, 2009; FREEZE; DITOMMASO, 2015; KENT; HERDENSON, 2017) pesquisaram a vida em comunidades religiosas, em conexão com o apego a Deus.

Namini; Murken (2009) realizaram uma pesquisa junto a pessoas que aderiram a movimentos religiosos recentes na Alemanha, incluindo participantes da Federação de Igrejas Pentecostais, da Nova Igreja Apostólica e das Testemunhas de Jeová. A adesão a esses movimentos "é frequentemente precedida por algum tipo de crise (relatada retrospectivamente), sendo que o bem-estar aumenta com o envolvimento" nesses movimentos (NAMINI; MURKEN, 2009, p. 61). 
As pesquisas de Freeze; Ditommaso (2015) oferecem suporte para conceituar o relacionamento da pessoa com sua comunidade de fé como sendo um processo de apego (FREEZE; DITOMMASO, 2015, p. 60). O estudo sugere que, para pessoas que creem, um apego seguro a Deus e à comunidade de fé prediz maior bem-estar, ao passo que apego inseguro a Deus e à família de fé prediz menor bem-estar (FREEZE; DITOMMASO, 2015, p. 68). Kent; Henderson (2017) também estudaram o apego a Deus e a vida congregacional e demonstraram que as características intrapessoais estruturam a dinâmica das congregações religiosas. Suas pesquisas sugerem que o apego seguro com Deus está positivamente associado à participação congregacional, ao passo que os apegos ansioso e evitante estão negativamente associados a essa participação (KENT; HENDERSON, 2017, p. 1).

Portanto, os estudos sobre apego e comportamento religioso confirmam que apegos seguros a Deus tendem a estar associados a avaliações mais positivas da comunhão com Deus, a uma correta avaliação dos atributos de Deus, a uma humildade sadia, ao aumento da religiosidade e espiritualidade, à redução da aflição emocional e a vínculos de apego com a comunidade de fé. Por outro lado, apegos inseguros a Deus tendem a estar associados a níveis mais elevados de sofrimento psicológico, a avaliações inadequadas dos atributos divinos, a classificar as situações estressantes como sendo batalhas espirituais, a mais aflição e a questionamentos da natureza e relevância de Deus.

\subsection{Apego a Deus e aconselhamento e cuidado espiritual}

Quatro publicações (KELLEY, 2009; THOMAS et al., 2011; RASAR et al., 2013; OLSON et al., 2016) trataram do apego a Deus no contexto do aconselhamento ou cuidado espiritual.

A partir da análise de dois estudos de caso em aconselhamento, Kelley (2009) destaca possíveis implicações do apego a Deus, no cuidado espiritual de pessoas em processo de luto. O relato dos pacientes indica uma forte correspondência entre seus estilos de apego aos pais e seus estilos de apego a Deus (KELLEY, 2009, p. 101). A partir desses estudos de caso, a autora identificou três desafios para os psicoterapeutas espiritualmente orientados. Primeiro, devemos reconhecer que a perda pode moldar a 
vida de uma pessoa de várias maneiras e isso pode complicar muito o processo de cura. Em segundo lugar, devemos nos perguntar como essas perdas podem ter moldado a capacidade da pessoa de experimentar Deus. O terceiro desafio é sermos fornecedores de esperança. $\mathrm{O}$ processo às vezes meticuloso de sentir segurança no relacionamento terapêutico pode render enormes dividendos no domínio do divino (KELLEY, 2009, p. 102).

Thomas et al. (2011) analisaram os efeitos de uma psicoterapia de grupo com duração de oito semanas sobre as imagens de Deus e o apego a Deus dos participantes. A terapia consistiu de intervenções psicoeducacionais, dinâmicas interpessoais e cognitivas, biblioterapia alegórica e intervenções através da arte e da música. Ao término da psicoterapia, os participantes reportaram menos ansiedade e menos evitação no apego a Deus (THOMAS et al., 2011, p. 44). Eles concluem que a aplicação de métodos estruturados para modificar o apego a Deus pode ser uma importante ferramenta no cuidado espiritual.

Rasar et al. (2013) investigaram a eficácia de um tratamento para mudar a imagem de Deus, o apego a Deus e o enfrentamento religioso, junto a estudantes de universidades cristãs. A pesquisa foi realizada mediante a criação de um grupo de formação espiritual, um grupo de estudo bíblico e um grupo de controle. Os resultados indicam o valor de grupos pequenos de formação espiritual ou de estudos bíblicos, uma vez que ambos os grupos exibiram mudanças significativas em todos os itens pesquisados, em comparação com o grupo de controle (RASAR et al., 2013, p. 274).

Olson et at. (2016) também focaram seus estudos sobre imagens de Deus e apego a Deus mediante a criação de três grupos, com duração de 9 semanas. No grupo de formação espiritual foi aplicado um material para tratar da imagem de Deus e do apego a Deus, mediante intervenções psicoeducacionais e discussão. No grupo de estudos bíblicos houve discussões em grupo, memorização de trechos bíblicos e incorporação de atividades de formação espiritual. O terceiro grupo era um grupo de controle. Contrariando as conclusões dos estudos de Thomas et al. (2011) e de Rasar et al. (2013), as pesquisas de Olson et al. (2016) sugerem que as mudanças no apego a Deus foram mais significativas no grupo de estudo da Bíblia (OLSON et al., 2016, p. 277). 
As pesquisas no campo do aconselhamento e cuidado espiritual apontam para o benefício de empregar os conceitos do apego a Deus. Os conceitos de um Deus que se importa e cuida podem ser empregados pelo conselheiro para promover uma autonomia e autoconfiança maiores do cliente no enfrentamento de dificuldades da vida e da aflição emocional. Se Deus estiver funcionando como uma figura de apego seguro para o cliente, pode-se esperar que o cliente encontre nesse relacionamento um porto seguro e uma base para lidar com o seu mundo, particularmente sob condições estressantes.

\section{Conclusão}

O presente estudo mostra que a produção empírica sobre apego a Deus está em crescimento, embora ainda estejam concentradas, em sua maioria, nos EUA e Inglaterra. A construção e validação de escalas para mensurar o apego a Deus tem favorecido as pesquisas empíricas, permitindo comparar resultados de diferentes pesquisas. Destaca-se o instrumento Attachment to God Inventory, utilizado em quase metade das publicações analisadas.

Os estudos demonstram a relevância do apego parental na maneira como a pessoa irá construir ou não uma relação de apego a Deus. O apego a Deus pode ser um meio importante para atenuar o sofrimento e para reparar os modelos internos de funcionamento da pessoa. Pessoas com apego seguro a Deus apresentam um aumento sadio da espiritualidade e adotam comportamentos que favorecem a saúde física e emocional. Pessoas com apego inseguro a Deus apresentam níveis elevados de instabilidade em sua espiritualidade e reportam mais aflição, podendo sofrer um declínio na saúde mental. Os conceitos de um Deus que se importa e cuida podem ser empregados pelo conselheiro para promover uma autonomia e autoconfiança maiores do cliente no enfrentamento de dificuldades da vida e da aflição emocional.

Trabalhos pioneiros publicados no Brasil sobre apego a Deus, os artigos de Esperandio; August (2014) e August; Esperandio (2015) contribuem para difundir os conceitos do apego a Deus junto à comunidade brasileira. Contudo, ainda não existe um instrumento de mensuração do apego a Deus validado para a realidade brasileira. 
Há poucas pesquisas empíricas que investigam a aplicação dos conceitos do apego a Deus no aconselhamento e cuidado espiritual. Portanto, novos estudos poderiam apontar maneiras de como terapeutas, conselheiros e cuidadores espirituais podem aplicar os conceitos do apego e do apego a Deus, visando oferecer um cuidado mais efetivo às pessoas que os procuram em busca de orientação e apoio espirituais. Também seriam muito úteis estudos longitudinais, que explorem como e em que circunstâncias os indivíduos alteram (ou não) seu estilo de apego a Deus. Considerando a importância da religiosidade no contexto cultural brasileiro, o aprofundamento do tema do apego a Deus seria de grande relevância para os campos da Teologia, da Psicologia e das Ciências das Religiões.

\section{REFERÊNCIAS}

ABREU, Cristiano Nabuco de. Teoria do apego: fundamentos, pesquisas e implicações clínicas. São Paulo: Casa do Psicólogo, 2005.

ANO, Gene G.; PARGAMENT, Kenneth. Predictors of spiritual struggles: an exploratory study. Mental Health, Religion \& Culture. Journal Article, v. 16, n. 4, p. 419-434, Apr. 2013.

AUGUST, Hartmut; ESPERANDIO, Mary Rute G. Teoria do apego: origem, desenvolvimento e perspectivas. In: COMISSÃO ORGANIZADORA DO V CONGRESSO DA ANPTECRE. Anais do V Congresso da ANPTECRE "Religião, Direitos Humanos e Laicidade”. Curitiba, v. 5, p. ST1111, 2015.

BECK, Richard. Communion and Complaint: attachment, object-relations, and triangular love perspectives on relationship with God. Journal of Psychology and Theology, v. 34, n. 1, p. 43-53, 2006a.

BECK, Richard. God as a secure base: attachment to God and theological exploration. Journal of Psychology and Theology, v. 34, n. 2, p. 125-133, $2006 \mathrm{~b}$.

BECK, Richard; MCDONALD, Angie. Attachment To God: The Attachment To God Inventory, Tests Of Working Model Correspondence, And An Exploration Of Faith Group Differences. Journal of Psychology and Theology, v. 32, n. 2, p. 92-103, 2004.

BELAVICH, Timothy G.; PARGAMENT, Kenneth I. The Role of Attachment in Predicting Spiritual Coping with a Loved One in Surgery. Journal of Adult Development, v. 9, n. 1, p. 13-29, Jan. 2002. 
BIRGEGARD, A.; GRANQVIST, P. The correspondence between attachment to parents and God: three experiments using subliminal separation cues. Personality and Social Psychology Bulletin, v. 30, n. 9, p. 1122-1135, Sept. 2004.

BOWLBY, John. Apego: a natureza do vínculo. 3. ed. São Paulo: Martins Fontes, 2002. v. 1. (trilogia Apego e Perda).

BOWLBY, John. Perda: tristeza e depressão. São Paulo: Martins Fontes, 2004a. v. 3. (trilogia Apego e Perda).

BOWLBY, John. Separação: angústia e raiva. São Paulo: Martins Fontes, 2004b. v. 2. (trilogia Apego e Perda).

BRADLEY, David F.; EXLINE, Julie J.; UZDAVINES, Alex. Relational reasons for nonbelief in the existence of gods: an important adjunct to intellectual nonbelief. Psychology of Religion and Spirituality, v. 9, n. 4, p. 319-327, 2017.

BRADSHAW, M.; ELLISON, C. G.; MARCUM, J. P. Attachment to God, Images of God, and Psychological Distress in a Nationwide Sample of Presbyterians. The International Journal for the Psychology of Religion, v. 20, n. 2, p. 130-147, 2010.

BRADSHAW, M.; KENT, B. V. Prayer, Attachment to God, and Changes in Psychological Well-Being in Later Life. Journal of Aging and Health, v. 30, n. 5, p. 667-691, Feb. 2017.

BRENNAN, K. A.; CLARK, C. L.; SHAVER, P. R. Self-report measures of adult romantic attachment - An integrative overview. In: J. A., Simpson; W. S. Rholes (ed.). Attachment theory and close relationships. Nova York: Guilford Press, 1998.

BRUCE, A. Jerry; COOPER, Laura B.; KORDINAK, S. T.; HARMAN, Marsha J. God and Sin After 50: Gender and Religious Affiliation. Journal of Religion, Spirituality \& Aging, v. 23, n. 3, p. 224-235, Jul.-Sep. 2011.

BUSER, Juleen K.; GIBSON, Sandy. Attachment to God/Higher Power and Bulimic Symptoms Among College Women. Journal of College Counseling, v. 19, n. 2, p. 124137, Jul. 2016.

CASSIBBA, Rosalinda; GRANQVIST, Pehr; COSTANTINI, Alessandro. Mothers' attachment security predicts their children's sense of God's closeness. Attachment \& Human Development, v. 15, n. 1, p. 51-64, 2013.

CASSIBBA, Rosalinda; GRANQVIST, Pehr; COSTANTINI, Alessandro; GATTO, Sergio. Attachment and god representations among lay Catholics, priests, and religious: A matched comparison study based on the adult attachment interview. Developmental Psychology, v. 44, n. 6, p. 1753-1763, Nov. 2008.

CASSIBBA, Rosalinda; PAPAGNA, Sonia; CALABRESE, Maria T.; COSTANTINO, Elisabetta; PATERNO, Angelo; GRANQVIST, Pehr. The role of attachment to God in secular and religious/spiritual ways of coping with a serious disease. Mental Health, Religion \& Culture, v. 17, n. 3, p. 252-261, Mar. 2014. 
CICIRELLI, V. G. God as the ultimate attachment figure for older adults. Attachment \& Human Development, v. 6, n. 4, p. 371-388, Dec. 2004.

COOPER, Laura B.; BRUCE, A. Jerry; HARMAN, Marsha J.; BOCCACCINI, Marcus T. Differentiated styles of attachment to God and varying religious coping efforts. Journal of Psychology and Theology, v. 37, n. 2, p. 134-142, 2009.

DUMONT, Karin; JENKINS, David; HINSON, Victor; SIBCY, Gary. God's shield: the relationship between god attachment, relationship satisfaction, and adult child of an alcoholic (ACOA) status in a sample of evangelical graduate counseling students. Journal of Psychology and Christianity, v. 31, n. 1, p. 51-66, 2012.

ELLISON, Christopher G.; BRADSHAW, Matt; FLANNELLY, Kevin J.; GALEK, Kathleen C. Prayer, Attachment to God, and Symptoms of Anxiety-Related Disorders among U.S. Adults. Sociology of Religion, v. 75, n. 2, p. 208-233, 2014.

ELLISON, Christopher G.; BRADSHAW, Matt; KUYEL, Nilay; MARCUM, Jack. Attachment to God, Stressful Life Events, and Changes in Psychological Distress. Review of Religious Research, v. 53, n. 4, p. 493-511, 2012.

ESPERANDIO, Mary Rute G.; AUGUST, Hartmut. Teoria do apego e comportamento religioso. Interações - Cultura e Comunidade, Belo Horizonte, v. 9, n. 16, p. 243-265, juldez. 2014.

FERGUS, Thomas A.; ROWATT, Wade C. Examining a purported association between attachment to God and scrupulosity. Psychology of Religion and Spirituality, v. 6, n. 3, p. 230-236, Aug. 2014.

FREEZE, Tracy A.; DITOMMASO, Enrico. An examination of attachment, religiousness, spirituality and well-being in a Baptist faith sample. Mental Health, Religion \& Culture, v. 17, n. 7, p. 690-702, Aug. 2014.

FREEZE, Tracy A.; DITOMMASO, Enrico. Attachment to God and church family: predictors of spiritual and psychological well-being. Journal of Psychology and Christianity, v. 34, n. 1, p. 60-73, 2015.

GHORBANI, Nima; WATSON, P. J.; OMIDBEIKI, Mahsa; CHEN, Zhuo Job. Muslim Attachments to God and the "Perfect Man" (Ensān-e Kāmel): Relationships With Religious Orientation and Psychological Adjustment in Iran. Psychology of Religion and Spirituality, v. 8, n. 4, p. 318-329, Nov. 2016.

GRANQVIST, P.; LJUNGDAHL, C.; DICKIE, J. R. God is nowhere, God is now here: attachment activation, security of attachment, and God's perceived closeness among 5-7year-old children from religious and non-religious homes. Attachment \& Human Development, v. 9, n. 1, p. 55-71, Mar. 2007 a.

GRANQVIST, Pehr. Building a bridge between attachment and religious coping: tests of moderators and mediators. Mental Health, Religion \& Culture, v. 8, n. 1, p. 35-47, Mar. 2005. 
GRANQVIST, Pehr. Mental health and religion from an attachment viewpoint: overview with implications for future research. Mental Health, Religion \& Culture, v. 17, n. 8, p. 777-793, Sep. 2014.

GRANQVIST, Pehr. Religiousness and Perceived Childhood Attachment: On the Question of Compensation or Correspondence. Journal for the Scientific Study of Religion, v. 37, n. 2, p. 350-368, Jun. 98.

GRANQVIST, Pehr; BROBERG, Anders G.; HAGEKULL, Berit. Attachment, religiousness, and distress among the religious and spiritual: links between religious syncretism and compensation. Mental Health, Religion \& Culture, v. 17, n. 7, p. 726-740, Aug. 2014.

GRANQVIST, Pehr; IVARSSON, Tord; BROBERG, Anders G.; HAGEKULL, Berit. Examining relations among attachment, religiosity, and new age spirituality using the Adult Attachment Interview. Developmental Psychology, v. 43, n. 3, p. 590-601, May 2007b.

GRANQVIST, Pehr; KIRKPATRICK, Lee A.; PARGAMENT, Kenneth I. (ed.).; EXLINE, Julie J. (ed.).; JONES, James W. (ed.). Religion, spirituality, and attachment. APA handbook of psychology, religion, and spirituality. Washington, DC, US: American Psychological Association, 2013. v. 1. p. 139-155.

GRANQVIST, Pehr; MIKULINCER, Mario; GEWIRTZ, Vered; SHAVER, Phillip R. Experimental findings on God as an attachment figure: Normative processes and moderating effects of internal working models. Journal of Personality and Social Psychology, v. 103, n. 5, p. 804-818, Nov. 2012.

GRANQVIST, Pehr; MIKULINCER, Mario; SHAVER, Phillip R. Religion as attachment: normative processes and individual differences. Personality and Social Psychology Review, v. 14, n. 1, p. 49-59, Feb. 2010.

HALL, Todd W.; FUJIKAWA, Annie; HALCROW, Sarah R.; HILL, Peter C.; DELANEY, Harold. Attachment to god and implicit spirituality: clarifying correspondence and compensation models. Journal of Psychology and Theology, v. 37, n. 4, p. 227-245, 2009.

HAZAN, C.; SHAVER, P. R. Romantic love conceptualized as an attachment process. Journal of Personality and Social Psychology, v. 52, n. 3, p. 511-524, 1987.

HOMAN, Kristin J. A mediation model linking attachment to God, self-compassion, and mental health. Mental Health, Religion \& Culture, v. 17, n. 10, p. 977-989, Dec. 2014.

HOMAN, Kristin J. Attachment to God mitigates negative effect of media exposure on women's body image. Psychology of Religion and Spirituality, v. 4, n. 4, p. 324-331, Nov. 2012.

HOMAN, Kristin J.; BOYATZIS, Chris J. The protective role of attachment to God against eating disorder risk factors: concurrent and prospective evidence. Eat Disorder, v. 18, n. 3, p. 239-258, May-Jun. 2010. 
HOMAN, Kristin J.; LEMMON, Valerie A. Attachment to God and eating disorder tendencies: The mediating role of social comparison. Psychology of Religion and Spirituality, v. 6, n. 4, p. 349-357, Nov. 2014.

HOMAN, Kristin J.; LEMMON, Valerie A. Perceived relationship with God moderates the relationship between social comparison and body appreciation. Mental Health, Religion \& Culture, v. 18, n. 6, p. 425-439, Jul. 2015. DOI: 10.1080/13674676.2015.1075481.

HORTON, K. D.; ELLISON, C. G.; LOUKAS, A.; DOWNEY, D. L.; BARRETT, J. B. Examining attachment to God and health risk-taking behaviors in college students. Journal of Religion and Health, v. 51, n. 2, p. 552-566, Jun. 2012. DOI: 10.1007/s10943-010-9380-5.

HOUSER, Melissa E.; WELCH, Ronald D. Hope, religious behaviors, and attachment to god: a trinitarian perspective. Journal of Psychology and Theology, v. 41, n. 4, p. 281298, 2013.

JANKOWSKI, Peter J.; SANDAGE, Steven J. Attachment to God and humility: Indirect Effect and Conditional Effects Models. Journal of Psychology and Theology, v. 42, n. 1, p. 70-83, 2014.

KELLEY, Melissa M. Loss Through the Lens of Attachment to God. Journal of Spirituality in Mental Health, v. 11, n. 1/2, p. 88-106, 2009. DOI: 10.1080/19349630902864200.

KELLEY, Melissa M.; CHAN, Keith T. Assessing the role of attachment to God, meaning, and religious coping as mediators in the grief experience. Death Studies, v. 36, n. 3, p. 199, 2012.

KENT, Blake Victor; BRADSHAW, Matt; DOUGHERTY, Kevin. Attachment to God, Vocational Calling, and Worker Contentment. Review of Religious Research, v. 58, n. 3, p. 343-364, 2016.

KENT, Blake Victor; BRADSHAW, Matt; UECKER, J. E. Forgiveness, Attachment to God, and Mental Health Outcomes in Older U.S. Adults: A Longitudinal Study. Research on Aging, v. 40, n. 5, p. 456-479, May 2017.

KENT, Blake Victor; HENDERSON, W. Matthew. Attachment to God, Tenure, Race, and Participation in Congregational Life. Review of Religious Research, v. 59, p. 319-340, 2017.

KIM, Choong Yuk; KIM, Sangwon; BLUMBERG, Fran; CHO, Jihee. Validation of the Korean Attachment to God Inventory. Psychology of Religion and Spirituality, v. 9, n. 1, p. 79-89, 2017.

KIRKPATRICK, Lee A. A Longitudinal Study of Changes in Religious Belief and Behavior as a Function of Individual Differences in Adult Attachment Style. Journal for the Scientific Study of Religion, v. 36, n. 2, p. 207-218, Jun. 97. 
KIRKPATRICK, Lee A. Attachment and religious representations and behavior. In: CASSIDY, J.; SHAVER, P. R. (ed.). Handbook of attachment: Theory, research, and clinical applications. New York: Guilford Press, 1999. p. 803-822.

KIRKPATRICK, Lee A. Attachment, Evolution, and the Psychology of Religion. Nova York: Guilford, 2005.

KIRKPATRICK, Lee A. God as a substitute attachment figure: a longitudinal study of adult attachment style and religious change in college students. Personality \& Social Psychology Bulletin, v. 24, n. 9, p. 961-974, Sept. 1998.

KIRKPATRICK, Lee A.; SHAVER, Phillip R. An attachment-theoretical approach of romantic love and religious belief. Personality and Social Psychology Bulletin, n. 18, p. 266-275, 1992.

KIRKPATRICK, Lee A.; SHAVER, Phillip R. Attachment Theory and Religion: Childhood Attachments, Religious Beliefs and Conversion. Journal for the Scientific Study of Religion, v. 29, n. 3, p. 315-335, Sep. 90.

KNABB, Joshua J.; PELLETIER, Joseph. The relationship between problematic Internet use, God attachment, and psychological functioning among adults at a Christian university. Mental Health, Religion \& Culture, v. 17, n. 3, p. 239-251, Mar. 2014.

KRAUSE, Neal; HAYWARD, R. David. Anxious Attachment to God, Spiritual Support, and Obesity: Findings from a Recent Nationwide Survey. Journal for the Scientific Study of Religion, v. 55, n. 3, p. 485, 2016.

LEVINE, Amir; HELlER, Rachel S. F. Apegados. Ribeirão Preto: Novo Conceito, 2013.

LIMKE, Alicia; MAYFIELD, Patrick B. Attachment to God: differentiating the contributions of fathers and mothers using the experiences in parental relationships scale. Journal of Psychology and Theology, v. 39, n. 2, p. 122-130, 2011.

MENDES, Karina Dal Sasso; SILVEIRA, Renata Cristina de Campos Pereira; GALVÃO, Cristina Maria. Revisão integrativa: método de pesquisa para a incorporação de evidências na saúde e na enfermagem. Texto contexto - enfermagem, Florianópolis, v. 17, n. 4, p. 758-764, dez. 2008.

MINER, Maureen. Back to the basics in attachment to God: revisiting theory in light of theology. Journal of Psychology and Theology, v. 35, n. 2, p. 112-123, 2007.

MINER, Maureen; GHOBARY-BONAB, Bagher; DOWSON, Martin. Development of a Measure of Attachment to God for Muslims. Review of Religious Research, v. 59, n. 2, p. 183-206, Jun. 2017.

MONROE, Natasha; JANKOWSKI, Peter J. The effectiveness of a prayer intervention in promoting change in perceived attachment to God, positive affect, and psychological distress. Spirituality in Clinical Practice, v. 3, n. 4, p. 237-249, Dec. 2016. 
NAMINI, S.; MURKEN, S. Self-chosen involvement in new religious movements (NRMs): well-being and mental health from a longitudinal perspective. Mental Health, Religion \& Culture, v. 12, n. 6, p. 561-585, Sep. 2009.

NJUS, David M.; OKERSTROM, Katrina. Anxious and avoidant attachment to god predict moral foundations beyond adult attachment. Journal of Psychology and Theology, v. 44, n. 3, p. 230-244, 2016.

OLSON, Trevor; TISDALE, Theresa Clement; DAVIS, Edward B.; PARK, Elizabeth A.; NAM, Jiyun; MORIARTY, Glendon L.; DAVIS, Don E.; THOMAS, Michael J.; CUTHBERT, Andrew D.; HAYS, Lance W. God image narrative therapy: A mixed-methods investigation of a controlled group-based spiritual intervention. Spirituality in Clinical Practice, v. 3, n. 2, p. 77-91, Jun. 2016.

PROCTOR, Marie-Therese; MINER, Maureen; MCLEAN, Loyola; DEVENISH, Stuart; GHOBARY-BONAB, Bagher. Exploring Christians' explicit attachment to God representations: the development of a template for assessing attachment to God experiences. Journal of Psychology and Theology, v. 37, n. 4, p. 245-265, 2009.

PROUT, Tracy A.; CECERO, John; DRAGATSI, Dianna. Parental object representations, attachment to God, and recovery among individuals with psychosis. Mental Health, Religion \& Culture, v. 15, n. 5, p. 449-466, Jun. 2012.

RASAR, Jacqueline D.; GARZON, Fernando L.; VOLK, Frederick; O'HARE, Carmella A.; MORIARTY, Glendon L. The efficacy of a manualized group treatment protocol for changing god image, attachment to god, religious coping, and love of god, others, and self. Journal of Psychology and Theology, v. 41, n. 4, p. 267-281, 2013.

RASHIDI, Mahsa; MOUSAVI, Fatemeh Sharif; ESMAEILI, Korosh. The Relationship between Styles of Attachment to God and Forgiveness and Empathy among Female Students in the City of Qom. Health, Spirituality and Medical Ethics, v. 3, n. 1, p. 1824, 2016.

REINER, Sarah R.; ANDERSON, Tamara L.; HALL, M. Elizabeth Lewis; HALL, Todd W. Adult attachment, God attachment and gender in relation to perceived stress. Journal of Psychology and Theology, v. 38, n. 3, p. 175-186, 2010.

REINERT, Duane F. Spirituality, Self-Representations, and Attachment to Parents: A Longitudinal Study of Roman Catholic College Seminarians. Counseling \& Values, v. 49, n. 3, p. 226-238, Apr. 2005.

REINERT, Duane F.; EDWARDS, Carla E. Attachment theory, childhood mistreatment, and religiosity. Psychology of Religion and Spirituality, v. 1, n. 1, p. 25-34, Feb. 2009.

REINERT, Duane F.; EDWARDS, Carla. Sex Differences in Religiosity: The Role of Attachment to Parents and Social Learning. Pastoral Psychology, v. 61, n. 2, p. 259-268, 2012. 
ROWATT, Wade; KIRKPATRICK, Lee A. Two Dimensions of Attachment to God and Their Relation to Affect, Religiosity, and Personality Constructs. Journal for the Scientific Study of Religion, v. 41, n. 4, p. 637-651, Dec. 2002.

SANDAGE, Steven J.; JANKOWSKI, Peter; CRABTREE, Sarah A.; SCHWEER, Maria. Attachment to God, adult attachment, and spiritual pathology: mediator and moderator effects. Mental Health, Religion \& Culture, v. 18, n. 10, p. 795-808, Dec. 2015.

SANDAGE, Steven J.; PAINE, David; HILL, Peter. Spiritual barriers to humility: a multidimensional study. Mental Health, Religion \& Culture, v. 18, n. 3, p. 207-217, Mar. 2015.

SIM, Tick N.; LOH, Bernice S. M. Attachment to God: Measurement and Dynamics. Journal of Social and Personal Relationships, v. 20, n. 3, p. 373-389, 6 Jan. 2003.

SIM, Tick N.; YOW, Amanda S. God attachment, mother attachment, and father attachment in early and middle adolescence. Journal of Religion and Health, v. 50, n. 2, p. 264-278, Jun. 2011. DOI: 10.1007/s10943-010-9342-y.

STRENGER, Alyssa M.; SCHNITKER, Sarah A.; FELKE, Thomas J. Attachment to God moderates the relation between sociocultural pressure and eating disorder symptoms as mediated by emotional eating. Mental Health, Religion \& Culture, v. 19, n. 1, p. 23-36, Jan. 2016. DOI: 10.1080/13674676.2015.1086324.

THOMAS, Michael J.; MORIARTY, Glendon L.; DAVIS, Edward B.; ANDERSON, Elizabeth L. The effects of a manualized group-psychotherapy intervention on client God images and attachment to God: a pilot study. Journal of Psychology and Theology, v. 39, n. 1, p. 44-59, spring 2011.

WEI, Meifen; KU, Tsun-Yao; CHEN, Hwei-Jane; WADE, Nathaniel; LIAO, Kelly Yu-Hsin; GUO, Gwo-Jen. Chinese Christians in America: Attachment to God, Stress, and WellBeing. Counseling and Values, v. 57, n. 2, p. 162-180, 2012. 